\title{
Current application and future perspectives of molecular typing methods to study Clostridium difficile infections
}

C W Knetsch ${ }^{1}$, T D Lawley², M P Hensgens ${ }^{1}$, J Corver $^{1}$, M W Wilcox ${ }^{3}$, E J Kuijper (E.J.Kuijper@lumc.nl) ${ }^{1}$

1. Section Experimental Microbiology, Department of Medical Microbiology, Center of Infectious Diseases, Leiden University Medical Center, Leiden, Netherlands

2. Bacterial Pathogenesis Laboratory, Wellcome Trust Sanger Institute, Hinxton, United Kingdom

3. Microbiology Department, Leeds Teaching Hospitals NHS Trust, Leeds, United Kingdom

Citation style for this article:

Knetsch CW, Lawley TD, Hensgens MP, Corver J, Wilcox MW, Kuijper EJ. Current application and future perspectives of molecular typing methods to study Clostridium difficile infections. Euro Surveill. 2013;18(4):pii=20381. Available online: http://www.eurosurveillance.org/ViewArticle.aspx?Articleld=20381

Article submitted on 25 July 2012 / published on 24 January 2013

Molecular typing is an essential tool to monitor Clostridium difficile infections and outbreaks within healthcare facilities. Molecular typing also plays a key role in defining the regional and global changes in circulating $C$. difficile types. The patterns of $C$. difficile types circulating within Europe (and globally) remain poorly understood, although international efforts are under way to understand the spatial and temporal patterns of $C$. difficile types. A complete picture is essential to properly investigate type-specific risk factors for $C$. difficile infections (CDI) and track longrange transmission. Currently, conventional agarose gel-based polymerase chain reaction (PCR) ribotyping is the most common typing method used in Europe to type $C$. difficile. Although this method has proved to be useful to study epidemiology on local, national and European level, efforts are made to replace it with capillary electrophoresis PCR ribotyping to increase pattern recognition, reproducibility and interpretation. However, this method lacks sufficient discriminatory power to study outbreaks and therefore multilocus variable-number tandem repeat analysis (MLVA) has been developed to study transmission between humans, animals and food. Sequence-based methods are increasingly being used for $C$. difficile fingerprinting/ typing because of their ability to discriminate between highly related strains, the ease of data interpretation and transferability of data. The first studies using whole-genome single nucleotide polymorphism typing of healthcare-associated $C$. difficile within a clinically relevant timeframe are very promising and, although limited to select facilities because of complex data interpretation and high costs, these approaches will likely become commonly used over the coming years.

\section{Introduction}

Clostridium difficile is a gram-positive rod-shaped anaerobic bacterium that is capable of forming spores. Since its discovery as a cause of antibiotic-associated pseudomembranous colitis nearly 30 years ago [1], C. difficile has become the major cause of antibiotic-associated diarrhoea. Antibiotics change the protective normal gut flora, which enables $C$. difficile to colonise the colon. Clinical symptoms may range from simple diarrhoea to severe colitis which can result in death [2]. Symptoms are primarily mediated by two virulence factors, toxins $A(\operatorname{tcd} A)$ and $B(\operatorname{tcd} B)$, which are released in the gut upon colonisation by $C$. difficile [3-5]. In the past decade, the epidemiology of $C$. difficile has changed and a new type emerged: polymerase chain reaction (PCR) ribotype (RT) 027/North American pulsed (NAP)-field type 01. Besides the production of toxins $A$ and $B$, the binary $C$. difficile transferase toxin $A / B$ (cdtA and cdtB) has probably contributed to the increased virulence of this type in addition to still unknown factors [6]. Major outbreaks due to this strain were reported since 2004, first in Canada followed by North America and Europe [7-10]. In 2008, PCR RTo78/ NAP07-08 was reported as an emerging strain [11]. To study the epidemiology of $C$. difficile, several molecular typing methods have been introduced. Ideally, a typing method must have sufficient discriminatory power, typeability (the ability to type isolates unambiguously), reproducibility and transportability (the ability to perform the method reproducibly in a fully compatible fashion in different laboratories at different times) and must be relatively easy to perform [12]. In this review, we describe the most commonly used typing methods to characterise $C$. difficile. In addition, we present the latest developments in typing of $C$. difficile. Finally, we discuss the use of typing in surveillance studies, to trace outbreaks and to study strain transmission from the environment to patients.

\section{Historical perspective of Clostridium difficile typing}

Molecular typing methods can be categorised into two groups, phenotypic and genotypic methods. In the 1980 s only phenotypic techniques were available. Serotyping using slide agglutination was commonly used in the mid-1980s. Initially, this assay was capable to differentiate six serogroups [13], later this 
Performance characteristics of various genotyping methods for Clostridium difficile

\begin{tabular}{|c|c|c|c|c|c|c|c|}
\hline Method & Target & $\begin{array}{l}\text { Discriminatory } \\
\text { power }\end{array}$ & Typeability & Reproducibility & $\begin{array}{c}\text { Ease of } \\
\text { interpretation }\end{array}$ & $\begin{array}{l}\text { Technical } \\
\text { complexity }\end{array}$ & Transportability \\
\hline \multicolumn{8}{|l|}{ Band-based } \\
\hline REA & Whole genome & Good & Fair & Fair & Poor & Moderate & Poor \\
\hline PFGE & Whole genome & Moderate & Fair & Moderate & Fair & Moderate & Moderate \\
\hline PCR ribotyping & $16 S-23$ S ISR & Good & Moderate & Moderate & Moderate & Low & Moderate \\
\hline Capillary PCR ribotyping & $16 \mathrm{~S}-23 \mathrm{~S}$ ISR & Excellent & Moderate & Good & Good & Moderate & Good \\
\hline MLVA & $\begin{array}{l}\text { Whole genome, } \\
\text { tandem repeats }\end{array}$ & Excellent & Poor & Moderate & Good & Moderate & Moderate \\
\hline \multicolumn{8}{|l|}{ Sequence-based } \\
\hline MLST 7 HG & $7 \mathrm{HG}$ & Good & Moderate & Moderate & Excellent & Moderate & Excellent \\
\hline SNP typing & $\begin{array}{c}\text { Whole genome, } \\
\text { SNPs }\end{array}$ & Excellent & Moderate & Moderate & Excellent & High & Good \\
\hline
\end{tabular}

HG: housekeeping genes; ISR: intergenic spacer region; MLST: multilocus sequence typing; MLVA: multilocus variable-number tandem repeat analysis; PCR: polymerase chain reaction; PFGE: pulsed-field gel electrophoresis; REA: restriction endonuclease analysis; SNP: single nucleotide polymorphism.

Table modified from Kuijper et al. [17].

was improved to 15 serogroups [14]. Other commonly used methods in this period were autoradiography polyacrylamide gel electrophoresis (radio PAGE) [15] and immunoblotting using rabbit antiserum prepared from rabbits immunised with four different $C$. difficile strains [16]. Phenotypic assays had low reproducibility, low typeability and insufficient discriminatory power to apply to epidemiological studies [12]. Genotypic techniques with better typeability and discriminatory power replaced phenotypic methods during the $1990 \mathrm{~s}$ [12]. Genotypic methods are divided into band-based and sequence-based methods. The most commonly used band-based methods were restriction endonuclease analysis (REA), pulsed-field gel electrophoresis (PFGE), capillary or conventional PCR ribotyping and multilocus variable-number tandem repeat analysis (MLVA), whereas the most frequently used sequencebased genotyping method was multilocus sequence typing (MLST). Recently whole genome sequencing (WGS) has emerged as a promising sequence-based technique as it allows the detection of variations between $C$. difficile strains by, for example, single nucleotide polymorphisms (SNPs) analysis. Here we present a brief summary of the current performance and costs of genotyping methods (Table 1 and 2), as a detailed description is beyond our scope and can be found in three other reviews on molecular typing $[12,17,18]$.

\section{Currently used typing methods for Clostridium difficile}

In Europe PCR ribotyping is presently the most frequently used typing method of $C$. difficile. This method was first applied by Gurtler et al. [21] and exploits the variability of the intergenic spacer region (ISR) between the $16 \mathrm{~S}$ and $23 \mathrm{~S}$ ribosomal DNA (rDNA), which is type-dependent. The variability, in combination with multiple copies of rDNA present in the genome, results in various amplicons after PCR amplification. These amplicons are separated by common agarose gel electrophoresis. The obtained banding patterns are referred to as PCR RTs. Two different sets of primers have been developed for typing of $C$. difficile $[22,23]$. The O'Neill primers described by Stubbs et al. [23] seem to have better discriminatory power than the Bidet primers [24]. The discriminatory power $(D)$ of a typing method is its ability to distinguish between unrelated strains, this D-value is based on Simpson's index of diversity [25]. PCR ribotyping is currently capable of identifying more than 400 distinct PCR RTs.

In North-America, PFGE is commonly used. PFGE of C. difficile involves digestion of genomic DNA with an infrequent cutting restriction enzyme, for example Smal [26]. PFGE allows separation of large DNA fragments which is not possible with conventional agarose gel electrophoresis. The obtained DNA fragments are separated using agarose gel electrophoresis with an electric field orientation repeatedly switching in three different directions (pulsed-field); one direction is through the central axis of the gel, whereas the other two are at an angle of 60 degrees on either side. The pulse time of the direction is linearly increased during the run so that progressively larger fragments are able to migrate forward through the gel, resulting into separation based on fragment size. The obtained banding patterns are referred to as NAP-field types. Unfortunately, standardisation of protocols and validation of PFGE for $C$. difficile have never progressed as they did for other food-borne pathogens on PulseNet at the United States (US) Centers for Disease Control and Prevention (CDC) [27]. 
Techniques, time and costs associated with various genotyping methods for Clostridium difficile

\begin{tabular}{|c|c|c|c|c|c|}
\hline \multirow{2}{*}{ Genotyping method } & \multirow{2}{*}{ Techniques } & \multirow{2}{*}{$\begin{array}{l}\text { Turnaround time } \\
\text { (post-culture) }\end{array}$} & \multirow{2}{*}{$\begin{array}{l}\text { Hands-on time } \\
\text { (post-culture) }\end{array}$} & \multicolumn{2}{|c|}{ Costs } \\
\hline & & & & Equipment $^{\mathrm{a}}$ & Per test ${ }^{\mathrm{b}}$ \\
\hline REA & DI, ER, GE & 2 days & 2 hours & Low & Low \\
\hline PFGE & DI, ER, GE & 2-4 days & 6 hours & Moderate & Low \\
\hline PCR ribotyping & DI, PCR, GE & $1-1.5$ days & 2 hours & Low/ moderate & Low \\
\hline Capillary ribotyping & DI, PCR, CE & 1 day & 2 hours & Moderate/ high & Low \\
\hline MLVA & DI, PCR, CE & 2 days & 8 hours & Moderate/ high & Low/ moderate \\
\hline MLST & DI, PCR, PPP, SE & 4 days & 8 hours & Moderate/ high & Moderate \\
\hline SNP typing & DI, LP, TA, SE & 5 days $^{c}$ & 3 days $^{d}$ & High & High \\
\hline
\end{tabular}

CE: capillary electrophoresis; DI: DNA isolation; ER: enzyme restriction; GE: gel electrophoresis; LP: library preparation; MLST: multilocus sequence typing; MLVA: multilocus variable-number tandem repeat analysis; PCR: polymerase chain reaction; PFGE: pulsed-field gel electrophoresis; PPP: PCR product purification; REA: restriction endonuclease analysis; SE: sequencing; SNP: single nucleotide polymorphism; TA: template amplification.

a Cost index for the equipment set-up: low < EUR 10,000<moderate < EUR 100,000< high.

${ }^{b}$ Cost index per test for materials: low $<$ EUR $10<$ moderate $<$ EUR $100<$ high.

' This estimated turnaround time is based on using Illumina Miseq benchtop sequencing [19].

${ }^{d}$ The hands-on time was determined by turnaround time substracted with the average runtime of the Illumina Miseq benchtop sequencer [20].

It has been reported that PFGE displays better discriminatory power than $P C R$ ribotyping with D-values of 0.843 and 0.688 , respectively [18]. In contrast, preliminary results of a study comparing different typing techniques on 39 of the most frequently found PCR RTs in Europe demonstrate that only 16 NAP-field types were obtained of 39 PCR RTs (personal communications, M Mulvey and D McCannel, 2011). A common concern with all band-based typing methods is the difficult interpretation of DNA banding patterns, especially when a DNA banding pattern differs marginally from the reference patterns. Consequently, appropriate definitions are required to identify new types with both PFGE and PCR ribotyping. In Europe, the Cardiff collection of Jon Brazier and Val Hall serves as a reference collection and new PCR RTs are always validated using this database. Currently, a clinical collection of 20 different $C$. difficile PCR RTs (European Centre for Disease Prevention and Control (ECDC)-Brazier collection) isolated from various European countries is available to distribute among all reference laboratories in Europe who participate in the European C. difficile infection study network (ECDISnet) [28]. The usage of two different standard typing methods in Europe and America has resulted into different nomenclatures, making interlaboratory exchange of data difficult. Already in 1994 Brazier et al. [29] emphasised the need for a unified nomenclature.

In 2004, MLST was introduced to study the population structure and global epidemiology of $C$. difficile [30]. This sequence-based typing method relies on sequencing of DNA fragments approximately ranging between 300 and $500 \mathrm{bp}$ representing seven housekeeping genes ( $M L S T$ THG). Sequence variants for each housekeeping gene are assigned with a distinct allele number and the combination of seven allele numbers (allelic profile) provides a sequence type (ST). MLST generates high-throughput sequence data that can be uploaded from laboratories worldwide to a common web database [31]. This facilitates ST calling as well as studying the population structure and global epidemiology of $C$. difficile. Two different typing schemes have been proposed in literature to characterise $C$. difficile isolates [30,32]. Both typing schemes consist of seven housekeeping genes of which three are shared (triosephosphate isomerase (tpi), recombinase A ( $r e c A)$ and superoxide dismutase A (soda). In contrast to the scheme published by Griffiths et al. [32], the MLST scheme described by Lemee et al. [30] was not widely adopted. This can be partially explained by the presence of a null allele on the D-alanine--D-alanine ligase $(d d l)$ locus of the Lemee scheme which failed to amplify in certain strains [32]. Recently, this locus in the Lemee scheme was replaced by the groEL gene [33].

It has been reported that the discriminatory power of MLST and PCR ribotyping is comparable $[18,32]$. For studying outbreaks at a local level, a typing method should have higher discriminatory power than PCR ribotyping and MLST. For instance an increase in incidence of a PCR RT or MLST ST in a hospital can provide us with a clue for an outbreak and is useful data for monitoring changes in type prevalence rates, but does not necessarily proves clonal spread of one strain. 
MLST is an appropriate tool for studying the phylogeny of $C$. difficile. Compared to a band-based typing method, such as PCR ribotyping, MLST is less vulnerable to recombination events. Recombination in a housekeeping gene would change the allelic profile on a single locus only. Even though the consequence would be a change of ST, this new ST would still be closely related to the original ST maintaining the phylogenetic link. Recombination of repeats present in the ISR between the $16 \mathrm{~S}$ and $23 \mathrm{~S}$ rDNA [34] might lead to the formation of a novel PCR RT without a clear phylogenetic link. However, the rate at which these recombination events occur and the predisposing factors are unknown. Phylogeny reconstruction with MLST revealed that $C$. difficile diversified into at least five well separated lineages during evolution $[32,35,36]$ and possibly a sixth monophyletic lineage [37]. The majority of STs were assigned to lineage 1 with no major subdivisions (Figure 1), but this result could be due to an unfortunate choice of housekeeping genes. Changing the housekeeping genes or adding housekeeping genes to the current MLST scheme might provide a better resolution of lineage 1 .

A major advantage of sequence-based typing methods like MLST is the ease of interpretation of the generated data. Sequence data are unambiguous and therefore objective, highly reproducible and easily exchangeable between laboratories. Moreover, many laboratories have submitted their sequences to a freely accessible C. difficile MLST database [31]. Currently (last updated: 21 Nov 2012), 176 different STs have been identified. A practical disadvantage of MLST remains the relatively high cost of sequencing multiple targets, which could partially explain why MLST has not replaced conventional PCR ribotyping in many European laboratories.

MLVA is a highly discriminatory molecular typing method that has been introduced to study outbreaks and identify routes of transmission between patients and hospitals [11,38-42]. MLVA relies on the amplification of short tandem repeats that vary in size and are dispersed throughout the genome. The obtained amplicons are separated with capillary electrophoresis followed by automated fragment analysis. Initially, two different typing schemes were published which both contain seven loci of which four are identical $[41,42]$. Each of the seven loci is designated with a number that corresponds to the sum of repeats present on that locus. A minimum spanning tree (MST) can be constructed, in which the summed tandem repeat difference (STRD) is used as a measure of genetic difference (Figure 2). Clonal clusters are defined by an STRD of $\leq 2$, and genetically related clusters are defined by an STRD of $\leq 10$ [11,41]. Broukhanski et al. [43] observed that two MLVA loci ( $\mathrm{F}_{3}$ and $\mathrm{H}_{9}$ ) were invariable, indicating that loci $\mathrm{F}_{3}$ and $\mathrm{H} 9$ did not contribute to the discriminatory power. In addition, Bakker et al. [44] reported that MLVA locus A6 is a null allele in PCR RTo78 and that for several other loci the PCR settings had to be optimised for PCR RTo78. Invariance of MLVA loci requires optimisation and validation of MLVA for individual PCR RTs. Currently, MLVA has been implemented as useful typing method to investigate $C$. difficile 027 outbreaks in the Netherlands, France and the United Kingdom (UK) $[38,45,46]$. In England, C. difficile infection (CDI) cases that are potentially linked, i.e. caused by isolates that share the same PCR RT and which are related in time and place, are investigated using MLVA. Notably, almost half of such presumed clusters are shown actually either to consist of unrelated isolates or a mixture of related and distinct strains [46].

\section{Recent developments in typing of Clostridium difficile}

\section{Variant multilocus variable-number \\ tandem repeat analysis typing schemes}

Recently, a modified MLVA (mMLVA) was developed, combining MLVA with PCR detection of several toxin genes (tcdA and tcdB, cdtB; and deletions in the toxin C gene (tcdC)) [37]. In addition, the number of MLVA loci was restricted to five excluding the invariable loci $\mathrm{F}_{3}$ and $\mathrm{H}$. Although the combination with toxin gene detection can be informative, it is not yet possible to correlate these data with specific $C$. difficile types, like PCR RT027/NAP01. This is partially because the presence of binary toxin genes combined with the 18 bp tcdC deletion is not restricted to PCR RTo27 strains $[37,47]$.

In a study by Manzoor et al. [48] the number of MLVA loci was increased to 15. This extended MLVA (eMLVA) scheme was able to discriminate clinically significant clusters while maintaining a good concordance with PCR ribotyping. Typing schemes containing only seven loci showed in contrast poor association with $P C R$ ribotyping $[41,42]$. These seven loci schemes can only be used as a subtyping method together with PCR ribotyping, whereas the extended MLVA can potentially replace both. It should be noted, however, that increasing the number of loci makes the method more laborious and increases the difficulty of data interpretation.

Wei et al. [49] screened 40 MLVA loci for developing an MLVA typing scheme that has a good concordance with PCR ribotyping and provides satisfactory data for studying outbreaks. From this study, it was concluded that typing schemes consisting of MLVA loci with low allelic diversity maintained a high correlation with PCR ribotyping, whereas typing schemes using MLVA loci with high allelic diversity were required to study outbreaks. To fulfil both purposes two different typing schemes were proposed comprising 10 loci with limited allelic diversity and four loci with highly variable allelic diversity.

Capillary polymerase chain reaction ribotyping Although PCR ribotyping has become widely used in many European laboratories for $C$. difficile surveillance, issues with pattern interpretation and limited access to a well standardised database are 


\section{FIGURE 1}

Phylogenetic structure of Clostridium difficile strains

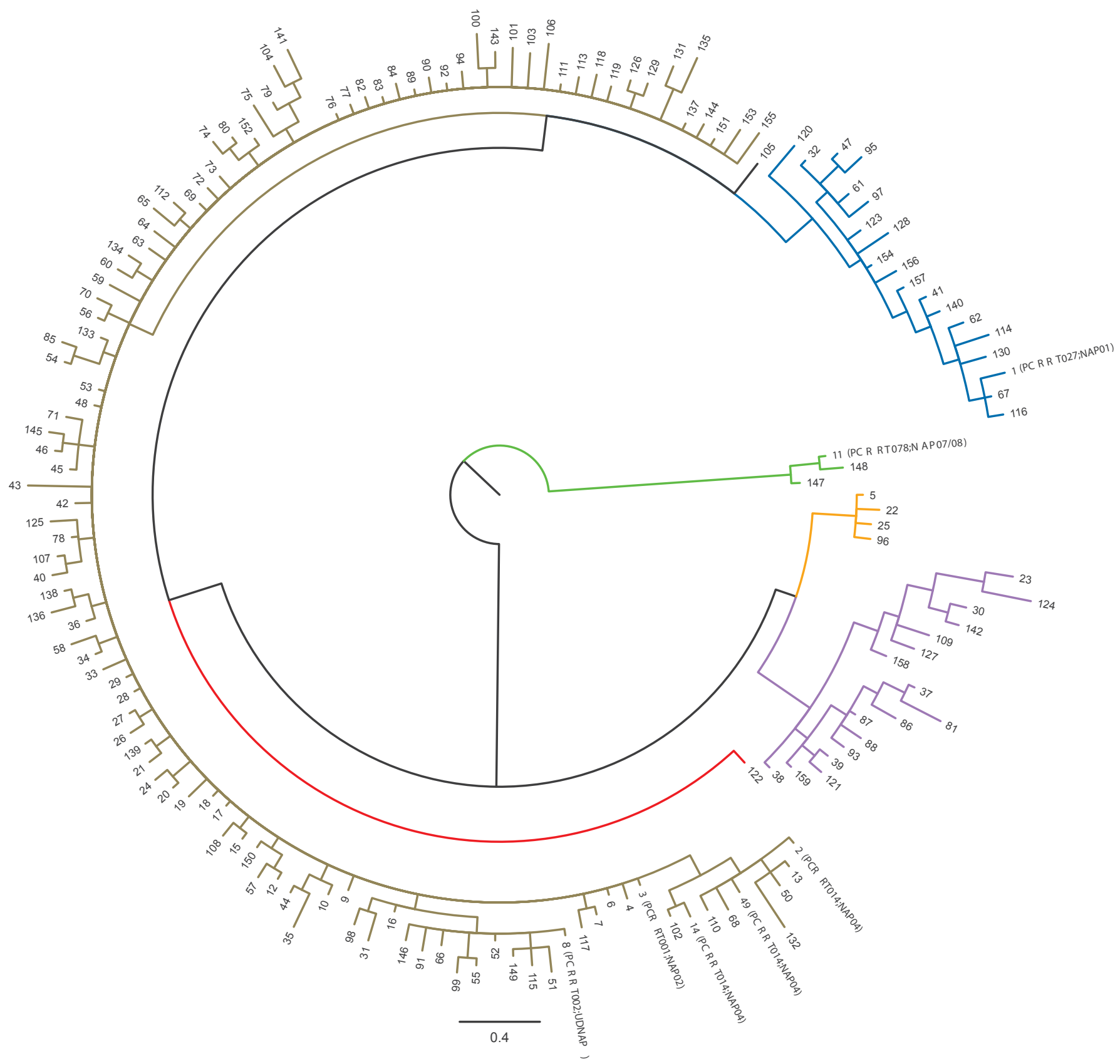

NAP: North American pulsed-field; PCR RTs: polymerase chain reaction ribotypes; UDNAP: undefined NAP field type.

The figure is modified from Knetsch et al. [37]. The phylogenetic tree (radial tree layout) was constructed using a bayesian posterior probability method based on the alignment of concatenated DNA sequences of seven housekeeping gene loci. Six major lineages are shown in colour. The PCR RTs and NAP field types of the five most frequently PCR RTs in Europe are shown between brackets and in bold. 


\section{FIGURE 2}

Minimum spanning tree illustrating distinct local Clostridium difficile outbreaks

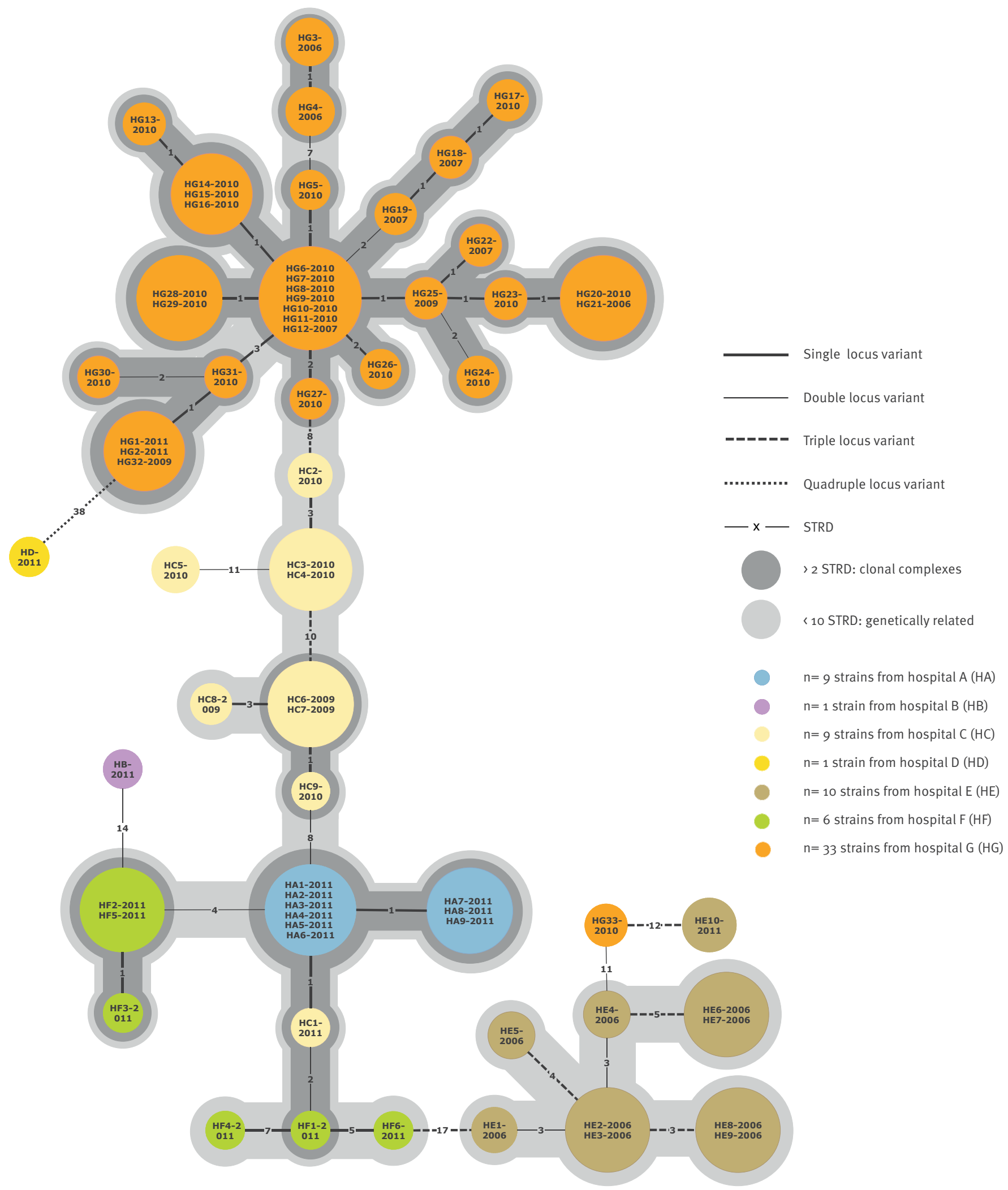

STRD: summed tandem repeat difference.

Multilocus variable-number tandem repeat analysis (MLVA) was used to recognise three different large local outbreaks in hospital G (orange), hospital A (blue) and hospital E (brown). Smaller outbreaks are indicated for hospital C (light yellow), hospital F (green) and related isolates from hospital B (purple) and hospital D (dark yellow). Clonal clusters are defined by a STRD of $\leq 2$, and genetically related clusters are defined by an STRD of $\leq 10$. 
important limitations. The adaptation of PCR ribotyping to high resolution capillary gel electrophoresis (CE) PCR ribotyping has greatly improved pattern reproducibility and interpretation. For instance, using conventional agarose gel-based PCR ribotyping, it is difficult to differentiate types 014 and 020 . In contrast, CE-PCR ribotyping can discriminate type 014 and type 020 and distinguish subtypes within type 014 [50]. However, the need for protocol standardisation remains evident. C. difficile surveillance laboratories from the $C D C$ in the US, Public Health Agency of Canada (PHAC) in Canada, Leiden University Medical Center (LUMC) in the Netherlands and Leeds Teaching Hospitals NHS Trust in the UK are collaborating to develop and validate a standardised protocol for the DNA extraction, primer sets, PCR cycling conditions, and reference standards for CE-PCR ribotyping. The standardised consensus protocol is tested on a well characterised collection of 70 different PCR RTs [37] distributed to each of the four laboratories. Preliminary results show consistent fingerprints between the laboratories. Peakfile-based analysis is currently being optimised and validated, with a conclusion available by mid-2013.

\section{Whole-genome single nucleotide} polymorphism typing

High-throughput, WGS of bacterial pathogens has reached a scale and reliability to accurately define the natural history and global population structures of virulent and epidemic lineages [51-55]. Phylogenetic and comparative genome analysis of hundreds (soon to be thousands) of genomes can identify precise genetic changes, often linked to virulence and antibiotic resistance phenotypes, that can quickly inform about the pathogen's biology. Whole genome sequencing can also distinguish between strains at the single nucleotide level, by comparing genomes in terms of single nucleotide polymorphisms, and therefore drastically improves the discriminatory power over conventional genetic typing methods. Thus, WGS has also (i.e. besides phylogeny) practical value for clinical microbiology and public health epidemiology by defining the selective forces that precipitate pathogen emergence and also by tracking transmission events ([56], Figure 3).

WGS approaches represent the ultimate pathogen typing method and, although its use and application remains limited to select facilities, we believe WGS will become a commonly used tool for $C$. difficile surveillance and epidemiology in the coming years. Although the cost of WGS is relatively high compared to traditional typing methods, sequencing costs are falling rapidly $[19,57]$. In addition, the ability to extrapolate MLST, PFGE, resistance gene, toxin gene sequence and other data from the same test could balance the costbenefit analysis. Standardised computational pipelines are emerging for $C$. difficile genome data quality control and subsequent downstream analysis associated with informatics, phylogeny and phylogeography (Figure 3). Improved high-quality draft genomes [58] for the most

\section{FIGURE 3}

General sequencing and analysis strategy used to track genomic variants of Clostridium difficile at local and global levels

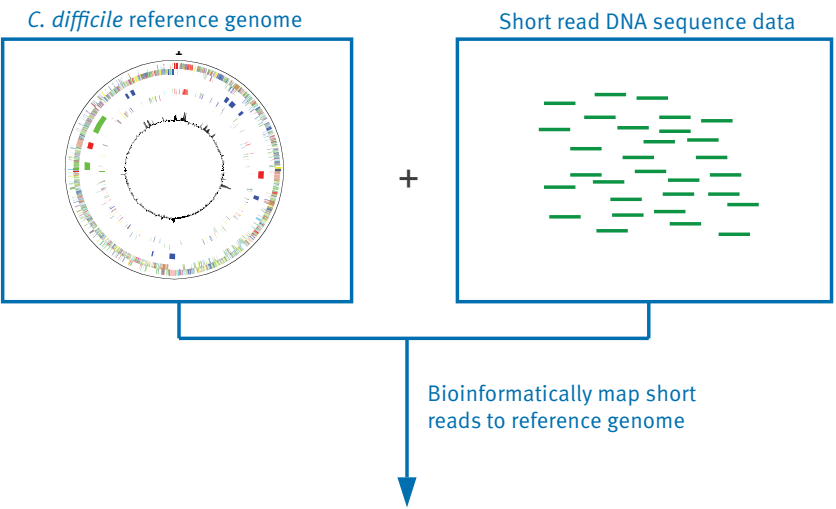

Determine population-level genome variation (e.g. SNPs, mobile elements, resistome)

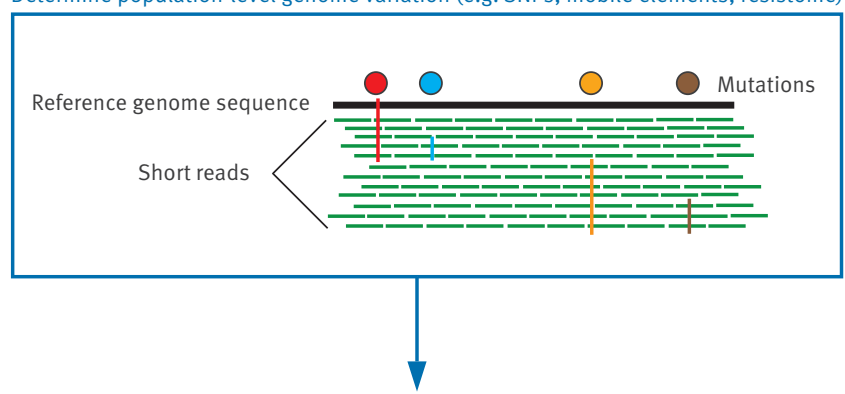

Determine phylogenetic relationship between isolates

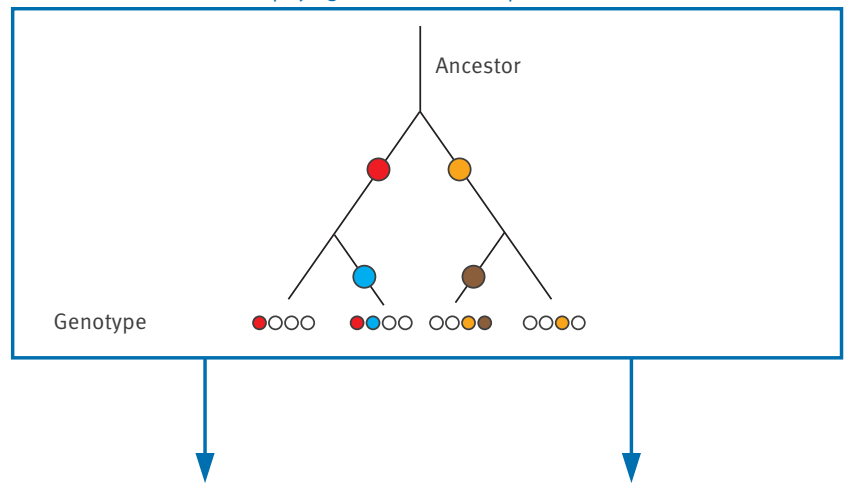

Link phylogeny to metadata (e.g. time/place of isolation, source, clinical data)

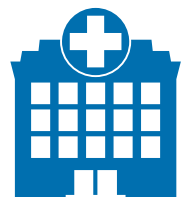

Healthcare transmission and persistence

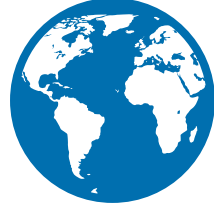

National/international spread
SNPs: single nucleotide polymorphisms.

Genomic DNA derived from Clostridium difficile isolates under study are subjected to sequencing with next generation sequencing technologies. Short read data from next generation sequencing platforms are mapped to reference genomes to determine the population level genome variation, such as SNPs, mobile element or other signatures of selection. Isolate sequences of interest are phylogenetically analysed. Combining phylogeny to epidemiological sequence data allows for inferences to be made about pathogen evolution and transmission events at healthcare and global level. 
common $C$. difficile variants causing disease in human and animal populations [59] serve as references to map next generation sequence data in order to detect variation within the core genome (genes shared by all organisms) or the accessory genome (genes present in only some organisms) [6o].

The first description of $C$. difficile PCR RTo27 phylogeny using high-throughput WGS demonstrated that 25 PCR RTo27 isolates from the US and Europe could be further discriminated into 25 distinct genotypes based on SNP analysis [54]. Furthermore, this study demonstrated that isolates from different regions of the US and Europe occupy distinct evolutionary lineages and harbour unique antibiotic resistance genes. More recently, it was demonstrated that PCR RTo27 isolates emerged through two distinct epidemic lineages after acquiring the same antibiotic resistance mutation; moreover these two lineages displayed different patterns of global spread [61]. The routine use of WGS in diagnostics and epidemiology is nicely reflected by the study of Koser et al. [62]. In this study it was reported that whole-genome SNP typing can be mainly used for monitoring outbreaks and recognition of pathogen transmission pathways. Current methods for monitoring $C$. difficile hospital associated outbreaks, such as PCR ribotyping, have too limited discriminatory power to characterise potential outbreak strains as the same bacterial clone. Sequencing of whole genomes offers the optimal discriminatory power allowing laboratories to detect transmission pathways between hospitals, hospital wards and patients on the same ward.

In addition, Eyre et al. [19] demonstrated that WGS can produce practical, clinically relevant data in a time frame that can influence patient management and infection control practice during an outbreak. Moreover, this study demonstrated that a cluster of healthcare-associated $C$. difficile cases caused by the same ST was in fact a number of unrelated sub-lineages, therefore allowing to rule out in patient-to-patient transmission. Furthermore, WGS combined with comparative genomics is an effective approach to identify novel genetic markers that are potentially linked to virulence. This is an important advantage above conventional typing methods that use existing markers for characterisation of isolates. Whole genome sequencing is not likely to replace routine diagnostic techniques in reference laboratories. For example, matrix-assisted laser desorption/ionisation (MALDI) time-of-flight (TOF), which is rapid and easy to perform, is currently used in the Dutch reference laboratory for primary detection of pathogens.

In order to determine whether sequenced isolates are part of an outbreak, it must be defined how many SNP differences still represent 'related' isolates. For that reason, we should be informed on the rate of SNP accumulation in C. difficile lifecycle (molecular clock), although bacterial isolates with a hypermutator phenotype could complicate the determination of such a threshold [56]. The molecular clock rate of $C$. difficile was reported at 2.3 SNPs/genome/year in the study done by Eyre et al. [19]. Further study is necessary to confirm this rate of $C$. difficile evolution.

\section{Application of typing methods to study the epidemiology of Clostridium difficile infections}

An obvious reason to type $C$. difficile isolates is to early detect and investigate outbreaks, which can be defined as 'a temporal increase in the incidence of a bacterial species caused by transmission of a certain strain' [63]. In addition, typing methods contribute to epidemiological surveillance on national, European or worldwide level and can be used to report the incidence of various $C$. difficile types and recognise newly emerging virulent types [63]. Typing might also establish the local and global spread of bacteria and elucidate routes of transmission.

In the beginning of the 21st century, a worldwide increase in the incidence of CDI was seen. Soon thereafter, it was recognised that a specific type of $C$. difficile, PCR RTo27, was linked to this increase of incidence $[7,9]$. PCR RTo27 was associated with specific predisposing factors, course and outcome of CDI. In a large Canadian outbreak, fluoroquinolones were associated with PCR RT027 and mortality rates among patients with this type increased to $23 \%$ within 30 days of diagnosis $[9,64]$. In the Netherlands, molecular typing of C. difficile using PCR ribotyping contributed to recognition of an outbreak of two simultaneously occurring PCR RTs (027 and 017) [45]. Again, patients had PCR RT-specific risk factors and mortality rates. Numerous studies demonstrated the increased virulence of PCR RTo27 [6-10] and found that other emerging types, such as PCR RTo78, were also associated with specific risk factors or complicated clinical course [11]. Without results from typing methods, these associations would have stayed unrecognised.

Molecular typing results can also be used to compare the distribution of various $C$. difficile types isolated from animals, humans and food, which can hint towards food-borne disease or zoonotic potential of specific PCR RTs. The emerging $C$. difficile PCR RTo78 in humans is found in high numbers in animals, especially piglets and calves [11,65-67]. Koene et al. [68] investigated the presence and characteristics of $C$. difficile in seven different animal species. PCR RTs 012, 014 and 078 were most frequently isolated among these Dutch animals, similar types were found among hospitalised patients in the Netherlands in 2009/2010. Meat consumption has also been suspected to contribute to transmission of $C$. difficile. PCR RTs 001, 017, 012 and 087 have been isolated from meat in Europe, however, isolation rates are low and might not be high enough to exceed the infectious dose [65-69]. Although PCR RTs in animals, meat and humans overlap, PCR ribotyping lacks discriminatory power to show clonal spread of $C$. difficile isolates from humans to animals. New 
molecular methods should be developed and applied. The optimised MLVA scheme developed by Bakker et al. [44] showed relatedness between human and porcine PCR RTo78 strains, although this could not always be confirmed with epidemiological data. Hopefully, highly discriminative typing methods such as wholegenome SNP typing can provide us with novel insights on zoonotic transmission.

\section{Importance of molecular typing for national surveillance by reference laboratories}

In Europe and North America, surveillance studies to monitor the incidence of $C D I$ and the spread of hypervirulent strains have been established at regional and national levels since 2007 although reporting of CDI is not mandatory in all European Union (EU) countries. To enhance surveillance for CDI, the ECDC and the US CDC advised to widely launch surveillance programmes for CDI [28]. Consequently, a European network to support capacity building for standardised surveillance of CDI was initiated by the ECDC [28].

When methods and data on existing national CDI surveillance systems in Europe were reviewed (personal communication, A Kola, 2012), surveillance of CDI was reported in $45 \%(14 / 31)$ of the European countries. Active surveillance of $C D I$ is performed in Austria, Norway, Belgium, Denmark, France, Germany, Ireland, Hungary, the Netherlands, Spain, Sweden, Luxembourg and the UK $[46,70-79]$. Surveillance was mostly continuous and prospective, but only four surveillance systems combined microbiological and epidemiological data (typing and susceptibility testing results) on a regular basis. A second recently completed survey in Europe (personal communication, D W Notermans, 2012) demonstrated that the majority of the laboratories were able to culture, but only half had access to typing. This limited typing capacity demonstrates the uncertainty of the true incidence levels of $C$. difficile types across Europe and hampers recognition of new emerging $C$. difficile types.

The contribution of national reference laboratories to survey $\mathrm{CDI}$ on a national level is illustrated by examples from the Netherlands and the UK. In 2005, soon after the emergence of $C$. difficile PCR RTo27, the Center for Infectious Disease Control (Clb) of the National Institute for Public Health and the Environment (RIVM) in the Netherlands started a national Reference Laboratory for $C$. difficile. In 2009, this laboratory noticed an emergence of a new virulent PCR RTo78, which was the third most frequently found type in the Netherlands among humans and was present in nearly all pig farms investigated $[11,67]$. Subsequently, this type was also found emerging in other European countries [80]. Recently, the reference laboratory noticed a re-emergence of $C$. difficile PCR RTo27 since 2010. In the period between May 2011 and May 2012, 289 samples from 26 healthcare facilities and laboratories in the Netherlands were submitted because of severe CDI cases or outbreaks.
PCR RTs 001 and 027 were the most commonly found (both $15.0 \%$ ). Interestingly, in contrast to a previous report of declining PCR RTo27 in hospitals in the Netherlands [81], type 027 was frequently identified in long-term care facilities associated with exchange of patients to neighbouring hospitals.

In the UK, the $C$. difficile Ribotyping Network (CDRN) was established in 2007, as part of improved CDI surveillance, to facilitate the detection and control of epidemic strains. Between 2007 and 2010, the CDRN received a large number of isolates $(n=11,294)$ for $P C R$ ribotyping. Typing results indicated that almost all of the 10 most common PCR RTs changed significantly during this time period [79]. As the proportion of CDI caused by PCR RTo27 declined (from 55\% to $21 \%$ ), significant increases were observed in the prevalence of other C. difficile types, especially PCR RTs 014/020, 015, 002, 078, 005, 023, and 016. In addition, there was a $61 \%$ reduction in reports of $C$. difficile in England from 2008 to 2011, which occurred coincidently as the proportion of CDI caused by C. difficile PCR RT027 declined. Notably, the large reduction in incidence of C. difficile PCR RTo27 cases has been paralleled by decreases in CDI related mortality [82]. The perceived success of the surveillance programme means that currently approximately a third of all CDI cases in England are referred to CDRN. CDI control programs should ideally include prospective access to $C$. difficile typing and analysis of risk factors for CDI and outcomes.

\section{Future perspective}

In the last fifteen years molecular genotyping methods have replaced some of the more traditional typing methods. WGS will dominate the field of molecular typing in the next decade. However, before WGS can be used as a routine tool for molecular typing some requirements need to be fulfilled. First, WGS needs to be fast, preferentially within 48 hours. Furthermore, the technical workflow including data analysis needs to be simplified into an automatic pipeline. Finally, the costs for acquiring the technical and organisational platform needed to perform WGS must be reduced. Fulfilling, these requirements, which is in our opinion a matter of time, would greatly increase the use of WGS worldwide.

\section{Acknowledgments}

This work was supported by ZonMw Grant 50-50800-98-079 from the Netherlands Organization for Scientific Research (NWO).

We would like to acknowledge the European Study group of Clostridium difficile on behalf of the European Society for Clinical Microbiology and Infectious Diseases (E.J.K.) for their contribution.

This work was funded by the European Centre for Disease Prevention and Control (ECDC) through the call for tender OJ/2010/07/09-PROC/2010/035. 


\section{References}

1. Bartlett JG. Antibiotic-associated pseudomembranous colitis. Hosp Pract (Off Ed). 1981;16(12):85-8, 93-5.

2. Kelly CP, Pothoulakis C, LaMont JT. Clostridium difficile colitis. N Engl J Med. 1994;330(4):257-62.

3. Voth DE, Ballard JD. Clostridium difficile toxins: mechanism of action and role in disease. Clin Microbiol Rev. 2005;18(2):247-63.

4. Kuehne SA, Cartman ST, Heap JT, Kelly ML, Cockayne A, Minton NP. The role of toxin A and toxin B in Clostridium difficile infection. Nature. 2010;467 (7316):711-3.

5. Lyras D, O'Connor JR, Howarth PM, Sambol SP, Carter GP, Phumoonna T, et al. Toxin B is essential for virulence of Clostridium difficile. Nature. 2009;458(7242):1176-9.

6. Schwan C, Stecher B, Tzivelekidis T, van Ham M, Rohde $M$, Hardt WD, et al. Clostridium difficile toxin CDT induces formation of microtubule-based protrusions and increases adherence of bacteria. PLoS Pathog. 2009;5(10):e1000626.

7. Kuijper EJ, Coignard B, Tüll P; ESCMID Study Group for Clostridium difficile; EU Member States; European Centre for Disease Prevention and Control. Emergence of Clostridium difficile-associated disease in North America and Europe. Clin Microbiol Infect. 2006;12 Suppl 6:2-18.

8. McDonald LC, Killgore GE, Thompson A, Owens RC Jr, Kazakova SV, Sambol SP, et al. An epidemic, toxin gene-variant strain of Clostridium difficile. N Engl J Med. 2005;353(23):2433-41.

9. Pépin J, Valiquette L, Cossette B. Mortality attributable to nosocomial Clostridium difficile-associated disease during an epidemic caused by a hypervirulent strain in Quebec. CMAJ. 2005;173(9):1037-42.

10. Warny M, Pepin J, Fang A, Killgore G, Thompson A, Brazier J, et al. Toxin production by an emerging strain of Clostridium difficile associated with outbreaks of severe disease in North America and Europe. Lancet. 2005;366(9491):1079-84.

11. Goorhuis A, Bakker D, Corver J, Debast SB, Harmanus C, Notermans DW, et al. Emergence of Clostridium difficile infection due to a new hypervirulent strain, polymerase chain reaction ribotype 078. Clin Infect Dis. 2008;47(9):1162-70.

12. Cohen SH, Tang YJ, Silva J Jr. Molecular typing methods for the epidemiological identification of Clostridium difficile strains. Expert Rev Mol Diagn. 2001;1(1):61-70.

13. Delmee M, Homel M, Wauters G. Serogrouping of Clostridium difficile strains by slide agglutination. J Clin Microbiol. 1985;21(3):323-7.

14. Tabaqchali S, Holland D, O'Farrell S, Silman R. Typing scheme for Clostridium difficile: its application in clinical and epidemiological studies. Lancet. 1984;1(8383):935-8.

15. Toma S, Lesiak G, Magus M, Lo HL, Delmée M. Serotyping of Clostridium difficile. J Clin Microbiol. 1988;26(3):426-8.

16. Mulligan ME, Peterson LR, Kwok RY, Clabots CR, Gerding DN. Immunoblots and plasmid fingerprints compared with serotyping and polyacrylamide gel electrophoresis for typing Clostridium difficile. J Clin Microbiol. 1988;26(1):41-6.

17. Kuijper EJ, van den Berg RJ, Brazier JS. Comparison of molecular typing methods applied to Clostridium difficile. Methods Mol Biol. 2009;551:159-71.

18. Killgore G, Thompson A, Johnson S, Brazier J, Kuijper E, Pepin J, et al. Comparison of seven techniques for typing international epidemic strains of Clostridium difficile: restriction endonuclease analysis, pulsed-field gel electrophoresis, PCR ribotyping, multilocus sequence typing, multilocus variablenumber tandem-repeat analysis, amplified fragment length polymorphism, and surface layer protein $A$ gene sequence typing. J Clin Microbiol. 2008;46 (2):431-7.

19. Eyre DW, Golubchik T, Gordon NC, Bowden R, Piazza P, Batty $E M$, et al. A pilot study of rapid benchtop sequencing of Staphylococcus aureus and Clostridium difficile for outbreak detection and surveillance. BMJ Open. 2012; 2(3).

20. Loman NJ, Misra RV, Dallman TJ, Constantinidou C, Gharbia SE, Wain J, et al. Performance comparison of benchtop high-throughput sequencing platforms. Nat Biotechnol. 2012;30(5):434-9.

21. Gürtler V. Typing of Clostridium difficile strains by PCRamplification of variable length 16S-23S rDNA spacer regions. Gen Microbiol. 1993;139(12):3089-97.

22. Bidet $P$, Barbut F, Lalande V, Burghoffer B, Petit JC. Development of a new PCR-ribotyping method for Clostridium difficile based on ribosomal RNA gene sequencing. FEMS Microbiol Lett. 1999;175(2):261-6.

23. Stubbs SL, Brazier JS, O’Neill GL, Duerden BI. PCR targeted to the 16S-23S rRNA gene intergenic spacer region of Clostridium difficile and construction of a library consisting of 116 different PCR ribotypes. J Clin Microbiol. 1999;37(2):461-3.
24. van den Berg RJ, Claas EC, Oyib DH, Klaassen CH, Dijkshoorn L, Brazier JS, et al. Characterization of toxin A-negative, toxin B-positive Clostridium difficile isolates from outbreaks in different countries by amplified fragment length polymorphism and PCR ribotyping. J Clin Microbiol. 2004; 42(3):1035-41.

25. Hunter PR, Gaston MA. Numerical index of the discriminatory ability of typing systems: an application of Simpson's index of diversity. J Clin Microbiol. 1988;26(11):2465-6.

26. Kristjánsson M, Samore MH, Gerding DN, DeGirolami PC, Bettin KM, Karchmer AW, et al. Comparison of restriction endonuclease analysis, ribotyping, and pulsed-field gel electrophoresis for molecular differentiation of Clostridium difficile strains. J Clin Microbiol. 1994;32(8):1963-9.

27. Centers for Disease Control and Prevention (CDC). PulseNet. Atlanta: CDC. [Accessed 1 Jul 2012]. Available from: http:// www.cdc.gov/pulsenet/

28. European Clostridium difficile infection study network (ECDIS NET). Europe: Supporting capacity building for surveillance of Clostridium difficile. Leiden: ECDIS-NET. [Accessed 1 Jul 2012]. Available from: http://www.ecdisnet.eu/

29. Brazier JS, Delmee M, Tabaqchali S, Hill LR, Mulligan ME, Riley TV. Proposed unified nomenclature for Clostridium difficile typing. Lancet. 1994;343(8912):1578-9.

30. Lemee L, Dhalluin A, Pestel-Caron M, Lemeland JF, Pons JL. Multilocus sequence typing analysis of human and animal Clostridium difficile isolates of various toxigenic types. J Clin Microbiol. 2004;42(6):2609-17.

31. Clostridium difficile MLST Databases. Clostridium difficile Multi Locus Sequence Typing website. Oxford: University of Oxford. [Accessed 21 nov 2012]. Available from: http:// pubmlst.org/cdifficile/

32. Griffiths D, Fawley W, Kachrimanidou M, Bowden R, Crook DW, Fung R, et al. Multilocus sequence typing of Clostridium difficile. J Clin Microbiol. 2010;48(3):770-8.

33. Institut Pasteur. Clostridium difficile MLST Database. Paris: Institut Pasteur. [Accessed: 1 jul 2012]. Available from: http:// www.pasteur.fr/recherche/genopole/PF8/mlst/Cdifficile2.html

34. Indra A, Blaschitz M, Kernbichler S, Reischl U, Wewalka G Allerberger $\mathrm{F}$. Mechanisms behind variation in the Clostridium difficile 16S-23S rRNA intergenic spacer region. J Med Microbiol. 2010;59(Pt 11):1317-23.

35. Dingle KE, Griffiths D, Didelot X, Evans J, Vaughan A, Kachrimanidou $M$ et al. Clinical Clostridium difficile: clonality and pathogenicity locus diversity. PLoS One. 2011; 6(5):e19993.

36. Stabler RA, Dawson LF, Valiente E, Cairns MD, Martin MJ, Donahue EH, et al. Macro and micro diversity of Clostridium difficile isolates from diverse sources and geographical locations. PLoS One. 2012;7(3):e31559.

37. Knetsch CW, Terveer EM, Lauber C, Gorbalenya AE, Harmanus C, Kuijper EJ, et al. Comparative analysis of an expanded Clostridium difficile reference strain collection reveals genetic diversity and evolution through six lineages. Infect Genet Evol. 2012;12(7):1577-85.

38. Eckert C, Vromman F, Halkovich A, Barbut F. Multilocus variable-number tandem repeat analysis: a helpful tool for subtyping French Clostridium difficile PCR ribotype 027 isolates. J Med Microbiol. 2011; 6o(Pt 8):1088-94.

39. Fawley WN, Freeman J, Smith C, Harmanus C, van den Berg RJ, Kuijper EJ, et al. Use of highly discriminatory fingerprinting to analyze clusters of Clostridium difficile infection cases due to epidemic ribotype 027 strains. J Clin Microbiol. 2008;46(3):954-60.

40. Lindstedt BA. Multiple-locus variable number tandem repeats analysis for genetic fingerprinting of pathogenic bacteria. Electrophoresis. 2005;26(13):2567-82.

41. Marsh JW, O'Leary MM, Shutt KA, Pasculle AW, Johnson S, Gerding DN, et al. Multilocus variable-number tandem-repeat analysis for investigation of Clostridium difficile transmission in Hospitals. J Clin Microbiol. 2006;44(7):2558-66.

42. van den Berg RJ, Schaap I, Templeton KE, Klaassen CH, Kuijper EJ. Typing and subtyping of Clostridium difficile isolates by using multiple-locus variable-number tandem-repeat analysis. J Clin Microbiol. 2007;45(3):1024-8.

43. Broukhanski G, Low DE, Pillai DR. Modified multiplelocus variable-number tandem-repeat analysis for rapid identification and typing of Clostridium difficile during institutional outbreaks. J Clin Microbiol. 2011;49(5):1983-6.

44. Bakker D, Corver J, Harmanus C, Goorhuis A, Keessen EC, Fawley WN, et al. Relatedness of human and animal Clostridium difficile PCR Ribotype 078 isolates based on multilocus variable-number tandem-repeat analysis and tetracycline resistance. J Clin Microbiol. 2010;48(10):3744-9.

45. Goorhuis A, Debast SB, Dutilh JC, van Kinschot CM, Harmanus C, Cannegieter SC, et al. Type-specific risk factors and outcome 
in an outbreak with 2 different Clostridium difficile types simultaneously in 1 hospital. Clin Infect Dis. 2011;53(9):860-9.

46. Fawley WN, Wilcox MH; Clostridium difficile Ribotyping Network for England and Northern Ireland. An enhanced DNA fingerprinting service to investigate potential Clostridium difficile infection case clusters sharing the same PCR ribotype. J Clin Microbiol. 2011;49(12):4333-7.

47. Janvilisri T, Scaria J, Thompson AD, Nicholson A, Limbago $B M$, Arroyo LG, et al. Microarray identification of Clostridium difficile core components and divergent regions associated with host origin. J Bacteriol. 2009;191(12):3881-91.

48. Manzoor SE, Tanner HE, Marriott CL, Brazier JS, Hardy KJ, Platt S, et al. Extended multilocus variable-number tandemrepeat analysis of Clostridium difficile correlates exactly with ribotyping and enables identification of hospital transmission. J Clin Microbiol. 2011;49(10):3523-30.

49. Wei HL, Kao CW, Wei SH, Tzen JT, Chiou CS. Comparison of PCR ribotyping and multilocus variable-number tandem-repeat analysis (MLVA) for improved detection of Clostridium difficile. BMC Microbiol. 2011;11:217.

50. Indra A, Huhulescu S, Schneeweis M, Hasenberger $P$, Kernbichler S, Fiedler A, et al. Characterization of Clostridium difficile isolates using capillary gel electrophoresis-based PCR ribotyping. J Med Microbiol. 2008;57(Pt 11):1377-82 .

51. Croucher NJ, Harris SR, Fraser C, Quail MA, Burton J, van der Linden $M$, et al. Rapid pneumococcal evolution in response to clinical interventions. Science. 2011;331(6016):430-4.

52. Harris SR, Feil EJ, Holden MT, Quail MA, Nickerson EK, Chantratita N, et al. Evolution of MRSA during hospital transmission and intercontinental spread. Science. 2010;327(5964):469-74.

53. Harris SR, Clarke IN, Seth-Smith HM, Solomon AW, Cutcliffe LT, Marsh P, et al. Whole-genome analysis of diverse Chlamydia trachomatis strains identifies phylogenetic relationships masked by current clinical typing. Nat Genet. 2012;44(4):413-9.

54. He M, Sebaihia M, Lawley TD, Stabler RA, Dawson LF, Martin MJ, et al. Evolutionary dynamics of Clostridium difficile over short and long time scales. Proc Natl Acad Sci U S A. 2010;107(16):7527-32.

55. Holt KE, Parkhill J, Mazzoni CJ, Roumagnac P, Weill FX, Goodhead I, et al. High-throughput sequencing provides insights into genome variation and evolution in Salmonella Typhi. Nat Genet. 2008;40(8):987-93.

56. Köser CU, Holden MT, Ellington MJ, Cartwright EJ, Brown NM, Ogilvy-Stuart AL, et al. Rapid whole-genome sequencing for investigation of a neonatal MRSA outbreak. N Engl J Med. 2012;366(24):2267-75.

57. Metzker ML. Sequencing technologies - the next generation. Nat Rev Genet. 2010;11(1):31-46.

58. Chain PS, Grafham DV, Fulton RS, Fitzgerald MG, Hostetler J, Muzny D, et al. Genomics. Genome project standards in a new era of sequencing. Science. 2009;326(5950):236-7.

59. Wellcome Trust Sanger Institute. Clostridium difficile genome data. Hinxton: Wellcome Trust Sanger Institute. [Accessed: 1 Nov 2012]. Available from: http://www.sanger.ac.uk/ resources/downloads/bacteria/clostridium-difficile.html

6o. Medini D, Donati C, Tettelin H, Masignani V, Rappuoli R. The microbial pan-genome. Curr Opin Genet Dev. 2005;15(6):589-94.

61. He M, Miyajima F, Roberts P, Ellison L, Pickard DJ, Martin MJ, et al. Emergence and global spread of epidemic healthcareassociated Clostridium difficile. Nat Genet. 2012;45(1):109-13.

62. Köser CU, Ellington MJ, Cartwright EJ, Gillespie SH, Brown NM, Farrington $\mathrm{M}$, et al. Routine use of microbial whole genome sequencing in diagnostic and public health microbiology. PLoS Pathog. 2012;8(8):e1002824.

63. van Belkum A, Tassios PT, Dijkshoorn L, Haeggman S, Cookson B, Fry NK, et al. Guidelines for the validation and application of typing methods for use in bacterial epidemiology. Clin Microbiol Infect. 2007;13 Suppl 3:1-46.

64. Pépin J, Saheb N, Coulombe MA, Alary ME, Corriveau MP, Authier $\mathrm{S}$, et al. Emergence of fluoroquinolones as the predominant risk factor for Clostridium difficile-associated diarrhea: a cohort study during an epidemic in Quebec. Clin Infect Dis. 2005;41(9):1254-60.

65. Hensgens MP, Keessen EC, Squire MM, Riley TV, Koene MG, de Boer $\mathrm{E}$, et al. Clostridium difficile infection in the community: a zoonotic disease? Clin Microbiol Infect. 2012;18(7):635-45.

66. Jhung MA, Thompson AD, Killgore GE, Zukowski WE, Songer G, Warny $M$, et al. Toxinotype $V$ Clostridium difficile in humans and food animals. Emerg Infect Dis. 2008;14(7):1039-45.

67. Keessen EC, Gaastra W, Lipman LJ. Clostridium difficile infection in humans and animals, differences and similarities. Vet Microbiol. 2011;153(3-4):205-17.
68. Koene MG, Mevius D, Wagenaar JA, Harmanus C, Hensgens MP, Meetsma AM, et al. Clostridium difficile in Dutch animals: their presence, characteristics and similarities with human isolates. Clin Microbiol Infect. 2012;18(8):778-84.

69. de Boer E, Zwartkruis-Nahuis A, Heuvelink AE, Harmanus C, Kuijper EJ. Prevalence of Clostridium difficile in retailed meat in the Netherlands. Int J Food Microbiol. 2011. 144(3):561-4.

70. Asensio A, Vaque-Rafart J, Calbo-Torrecillas F, Gestal-Otero J, Lopez-Fernandez F, Trilla-Garcia A, et al. Increasing rates in Clostridium difficile infection (CDI) among hospitalised patients, Spain 1999-2007. Euro Surveill. 2008;13(31):pii=18943. Available from: http://www. eurosurveillance.org/ViewArticle.aspx?Articleld=18943

71. Birgand G, Blanckaert K, Carbonne A, Coignard B, Barbut F, Eckert C, et al. Investigation of a large outbreak of Clostridium difficile PCR-ribotype 027 infections in northern France, 2006-2007 and associated clusters in 2008-2009. Euro Surveill. 2010;15(25):pii=19597. Available from: http://www. eurosurveillance.org/ViewArticle.aspx?Articleld=19597

72. Indra A, Huhulescu S, Fiedler A, Kernbichler S, Blaschitz $M$, Allerberger F. Outbreak of Clostridium difficile 027 infection in Vienna, Austria 2008-2009. Euro Surveill. 2009;14(17):pii=19186. Available from: http://www. eurosurveillance.org/ViewArticle.aspx?Articleld=19186

73. Ingebretsen A, Hansen G, Harmanus C, Kuijper EJ. First confirmed cases of Clostridium difficile PCR ribotype 027 in Norway. Euro Surveill. 2008;13(2):pii=8011. Available from: http://www.eurosurveillance.org/ViewArticle. aspx?Articleld $=8011$

74. Kleinkauf N, Weiss B, Jansen A, Eckmanns T, Bornhofen B, Küehnen E, et al. Confirmed cases and report of clusters of severe infections due to Clostridium difficile PCR ribotype 027 in Germany. Euro Surveill. 2007;12(46): pii=3307. Available from: http://www.eurosurveillance.org/ViewArticle. aspx?Articleld $=3307$

75. Kotila SM, Virolainen A, Snellman M, Ibrahem S, Jalava J, Lyytikäinen $O$. Incidence, case fatality and genotypes causing Clostridium difficile infections, Finland, 2008. Clin Microbiol Infect. 2011;17(6):888-93.

76. Suetens C. Clostridium difficile: summary of actions in the European Union. Euro Surveill. 2008;13(31): pii=18944. Available from: http://www.eurosurveillance.org/ViewArticle. aspx?Articleld $=18944$

77. Terhes G, Urbán E, Konkoly-Thege M, Székely E, Brazier JS, Kuijper EJ, et al. First isolation of Clostridium difficile PCR ribotype 027 from a patient with severe persistent diarrhoea in Hungary. Clin Microbiol Infect. 2009;15(9):885-6.

78. Viseur N, Lambert M, Delmee M, Van Broeck J, Catry B (2011) Nosocomial and non-nosocomial Clostridium difficile infections in hospitalised patients in Belgium - compulsory surveillance data from 2008 to 2010. Euro Surveill. 16(43): $\mathrm{pii}=20000$. Available from: http://www.eurosurveillance.org/ViewArticle. aspx?Articleld $=20000$

79. Wilcox MH, Shetty N, Fawley WN, Shemko M, Coen P, Birtles $A$, et al. Changing epidemiology of Clostridium difficile infection following the introduction of a national ribotyping based surveillance scheme in England. Clin Infect Dis. 2012;55(8):1056-63.

8o. Bauer MP, Notermans DW, van Benthem BH, Brazier JS, Wilcox MH, Rupnik M, et al. Clostridium difficile infection in Europe: a hospital-based survey. Lancet. 2011;377(9759):63-73.

81. Hensgens MP, Goorhuis A, Notermans DW, van Benthem $\mathrm{BH}$, Kuijper Ej. Decrease of hypervirulent Clostridium difficile PCR ribotype 027 in the Netherlands. Euro Surveill. 2009;14(45): pii=19402. Available from: http://www. eurosurveillance.org/ViewArticle.aspx?Articleld=19402

82. Office for National Statistics (ONS). Deaths Involving Clostridium Difficile - England and Wales, 2006 to 2010. Newport: ONS. [Accessed: 1 Jul 2012]. Available from: http:// www.ons.gov.uk/ons/rel/subnational-health2/deathsinvolving-clostridium-difficile/2006-to-2010/statisticalbulletin.html 